\title{
Physical fitness standards in students from the province of Neuquén, Argentina. Physical Fitness Assessment Plan study
}

\author{
Mauro D. Santander, MSc.a,b*, Gastón C. García, B.S. ', Jeremías D. Secchi, MSc. ${ }^{d}$, \\ Prof. Marcos Zuñiga ${ }^{a}$, Prof. Manuel Gutiérrez ${ }^{a}$, Prof. Nerea Salas ${ }^{a}$ and \\ Carlos R. Arcuri, B.S. eff
}

a. Department of Sports of Neuquén, province of Neuquén.

b. Higher Education Training Institute (Instituto de Formación en Educación Superior, IFES), province of Neuquén.

c. Department of Research, Superior Teacher Training Institute, San Rafael, province of Mendoza.

d. Teacher Certification in Physical Education, Universidad Adventista del Plata, Libertador San Martín, province of Entre Ríos.

e. Universidad Nacional de Catamarca, School of Health Sciences, province of Catamarca.

f. Department of Sports, government of the Autonomous City of Buenos Aires (GCABA).

Argentina.

E-mail address:

Mauro Darío Santander, MSc.: maurosantander@ hotmail.com

\section{Funding:}

The Ministry of Sports of the province of Neuquén, former Department of Sports, has provided the human resources and financial funds for this study.

Received: 9-22-2018

Accepted: 5-4-2019

\section{ABSTRACT}

Introduction. At present, there is no information about the physical fitness (PF) of children and adolescents attending school in the province of Neuquén. The provincial Department of Sports developed the Physical Fitness Assessment Plan. The main objective of this study was to administer the ALPHA-Fitness test battery to the students of Neuquén in order to develop PF reference standards.

Population and methods. A total of 4487 maleand female students of Neuquén aged 9-18.9 years were assessed based on four PF components of the high priority ALPHA-Fitness test battery: 1) morphological: body weight and height to estimate body mass index; 2 ) musculoskeletal: standing longjump test; 3 ) motor: $4 \times 10 \mathrm{~m}$ speed/ agility test; and 4) cardiorespiratory: 20 -m shuttle run test (SRT)

Results. The mean body mass index was $22.9 \pm 4.7 \mathrm{~kg} / \mathrm{m}^{2} ; 25 \%$ of participants were overweight and $12.7 \%$, obese. The mean values for the cardiorespiratory component were $4.3 \pm 2.5$ stages, $10.1 \pm 1.2 \mathrm{~km} / \mathrm{h}$, maximal oxygen volume of $38.7 \pm 6.7 \mathrm{~mL} / \mathrm{kg} / \mathrm{min}$; standing long jump: $147.3 \pm 34.6 \mathrm{~cm}$; and for the motor component: $13.0 \pm 1.5 \mathrm{~s}$. Male participants had a better performance in PF tests $(p<0.001)$.

Conclusion. The study results provide the first PF standards for male and female children and adolescents of the province of Neuquén, Argentina.

Key words: Stress test, 20-m SRT, reference standards, ALPHA-Fitness.

http: / / dx.doi.org/10.5546/ aap.2019.eng.e568

To cite: Santander MD, García GC, Secchi JD, Zuñiga $\mathrm{M}$, et al. Physical fitness standards in students from the province of Neuquén, Argentina. Physical Fitness Assessment Plan study. Arch Argent Pediatr 2019;117(6):e568-e575.

\section{INTRODUCTION}

Physical fitness (PF) is defined as a set of attributes that people acquire or develop and that allow them to do physical activity and exercise. Attributes refer to a complete range of physical qualities, such as aerobic capacity and power, muscle strength, balance, agility, speed, and flexibility. When assessed, these attributes reflect the performance status of different organs, systems, and structures related to physical activity and exercise. $^{2}$

Recent studies have demonstrated that moderate and high levels of PF in children and adolescents, specifically cardiorespiratory fitness and muscle strength, decrease the risk for metabolic disorders, increase bone mineral density, reduce depression symptoms, improve emotional, social, and cognitive well-being, and increase motor competence, among other things. ${ }^{3-6}$

For this reason, several investigators consider that $\mathrm{PF}$ is one of the most important markers of health in children and adolescents ${ }^{3}$ and should be taken into account in school assessments in relation to health knowledge and promotion. ${ }^{7}$

The ALPHA-Fitness test battery has proven to be valid and reliable to measure PF in relation to health in children and adolescents. ${ }^{8,9}$ By way of clarification, the assessment consists in two stages: measurement and assessment. Measurement covers the administration of the ALPHA-Fitness test battery to obtain the information (performance) of the different PF components, whereas assessment consists in considering the values 
obtained using reference standards. ${ }^{7}$ For the second stage, it is necessary to have national, provincial and/or specific standards from the region where the test battery is administered.

In Argentina, only one study has published PF reference values; ${ }^{10}$ however, given the number of students assessed, it was not representative at a national level. Besides, that study did not include students of Neuquén. In addition to the above, we did not find evidence of any $\mathrm{PF}$ assessment program and / or any reference standards developed in the province of Neuquén. For these reasons, there is no current knowledge of PF characteristics in the students of Neuquén.

The main objective of this study was to administer the high priority ALPHA-Fitness test battery to a representative sample of students of Neuquén in order to develop reference standards. They may be useful for school, sports and/or municipal institutions to compare PF among different age groups, students, classes, schools, provinces, and countries. ${ }^{7}$ They may also help to make decisions to design physical activity programs and promote health and physical education at school. ${ }^{7,11}$

\section{POPULATION AND METHODS Design and sample}

The study was conducted between May $2^{\text {nd }}$, 2015 and September $30^{\text {th }}, 2016$. The sample was made up of children and adolescents aged 9-18.9 years living in the province of Neuquén, Argentina. The study design was observational, descriptive, and cross-sectional. For sample representativeness, the study population was divided into three regions: North, Center, and South. The following sample sizes were determined: The North region $(\mathrm{n}=314)$ showed a $95 \%$ reliability (precision error: $6 \%$ ); the Center region $(\mathrm{n}=3089)$, a $99 \%$ reliability (precision error: $3 \%)$; and the South region $(n=1084)$, a $99 \%$ reliability (precision error: $5 \%$ ). This resulted in a sample of 4173 subjects. A total of 42 public schools participated (15 primary schools and 27 secondary schools). The geographic distribution was based on operational feasibility. Rural schools and shelters were excluded ( $2^{\text {nd }}$ stage: provincial project). All students obtained medical authorization for participation. Subjects with a clinical diagnosis (diabetes, asthma, musculoskeletal conditions or other) that limited their physical activity were not included in the study. Parents' and students' written informed consent was obtained. The project was assessed and supported by the Department of Sports and the Ministry of Education of the province of Neuquén, and research ethical guidelines were approved and followed. The project was called Physical Fitness Assessment Plan (Plan de Evaluación de la Condición Física, PECF).

\section{Procedures}

Before starting the study, investigators, physical education teachers, and observers conducted four theoretical-practical sessions to review the testing protocol, the assessment methodology, and data collection methods to standardize the assessment process as per published protocols. ${ }^{9}$ In addition, before the study, teachers administered the ALPHA test battery at the schools so that students would get used to the tests.

\section{Physical fitness assessment}

The high priority ALPHA-Fitness test battery version ${ }^{9}$ was administered in the following order: 1) Morphological component: Body weight and height were measured in accordance with the specified protocols. Weight was recorded with the participants barefoot and wearing clothes (T-shirt and long pants) using a portable electronic scale (OMROM HBF-500INT), with a $0.100 \mathrm{~kg}$ precision. Height was recorded using a stadiometer (SECA 206). Body mass index (BMI: $\mathrm{kg} / \mathrm{m}^{2}$ ) was estimated by dividing the subject's body weight by the square of the height in meters. Participants were identified as being overweight or obese based on Cole's criteria. ${ }^{12}$

2) Musculoskeletal component: The standing long jump (SLJ) was used as an indicator of lower limb strength. It consisted in jumping the longest distance possible from a standing start (without racing ahead), with both feet and swinging both arms. The distance was measured from the take-off line to the point where the back of the heel nearest to the takeoff line landed on the ground.

3) Motor component: The $4 \times 10 \mathrm{~m}$ speed/ agility test was used. It consisted in running back and forth between two lines $10 \mathrm{~m}$ apart taking three sponges alternately as quickly as possible. The total distance run was $40 \mathrm{~m}$.

4) Cardiorespiratory component: This was assessed using the 20-meter shuttle run test (20-m SRT), also known as course-navette. ${ }^{13}$ It consisted in running back and forth in both 
directions on a $20 \mathrm{~m}$ track marked between two separate lines for as long as possible. The rhythm was set by means of audio signals. The initial speed was $8.5 \mathrm{~km} / \mathrm{h}$ and was increased by $0.5 \mathrm{~km} / \mathrm{h}$ intervals every 1 minute. Subjects had to step behind the $20 \mathrm{~m}$ line at the exact time that the audio signal or beep was heard. The test finished when the subject stopped because of fatigue or failed to reach the end line concurrent with the beep on two consecutive occasions. Test performance was recorded using the number of 20-m laps (1 lap = $20 \mathrm{~m})$, the stage, and the final speed reached (FSR) in the last stage. The maximal oxygen volume $\left(\mathrm{VO}_{2 \max }\right)$ was estimated based on the following equation: ${ }^{14}$

$\mathrm{VO}_{2 \max }=31.025+3.238$ * S -3.248 * $\mathrm{A}+0.1536{ }^{*} \mathrm{~S}$ * $\mathrm{A}$

$\mathrm{S}$ : speed $(\mathrm{km} / \mathrm{h})$. A: age (years).

Two measurements were recorded for each test, except for the 20-m SRT, which was assessed only once. The best test performance was used for data analysis.

\section{Statistical analysis}

Data were analyzed using the SPSS 22.0 statistical software package. Before analysis, the Kolmogorov-Smirnov test (for normality) and the Levene test (for homoscedasticity) were done. Then, descriptive statistics were established (mean, standard deviation, maximal and minimal values). The Mann-Whitney $U$, a non-parametric test, was used to determine significant differences among outcome measures (if normality was not established). A value of $p<0.05$ (alpha) was accepted in all cases. Percentile tables were developed using the Least-Mean-Square algorithm (LMS) to smooth curves and with the LMS Chart Maker Light software, version 2.4. Due to the small number of participants (both males and females) in the 9-year-old group, tables were developed for age groups from 10 to 18 years.

\section{RESULTS}

A total of 4487 students were assessed ( $45 \%$ were males and $55 \%$, females). Participants were considered children if they were aged 9.0 to 12.9 years and adolescents if they were between 13.0 and 18.9 years. ${ }^{10}$ The sample characteristics and the values obtained in the PF tests are detailed in Table 1.

Male participants had a better performance in PF tests $(p<0.001)$. Height, weight, and BMI were different between adolescent males and females. The number of overweight and obese participants was different in the child group.

TABLE 1. Differences in physical fitness levels of children and adolescents of Neuquén, Argentina, by sex

\begin{tabular}{|c|c|c|c|c|c|c|c|c|c|c|c|c|c|c|c|c|c|}
\hline \multirow{3}{*}{$\begin{array}{l}\text { Physical fitness } \\
\text { components }\end{array}$} & \multicolumn{9}{|c|}{ Children aged 9-12.9 years } & \multicolumn{8}{|c|}{ Adolescents aged $13-18.9$ years } \\
\hline & \multicolumn{3}{|c|}{ All } & \multicolumn{3}{|c|}{ Male } & \multicolumn{3}{|c|}{ Female } & \multirow{2}{*}{$P$} & \multicolumn{3}{|c|}{ Male } & \multicolumn{3}{|c|}{ Female } & \multirow{2}{*}{$P$} \\
\hline & $\mathrm{N}$ & Mean & SD & $\mathrm{N}$ & Mean & SD & $\mathrm{N}$ & Mean & SD & & $\mathrm{N}$ & Mean & & $\mathrm{N}$ & Mean & SD & \\
\hline \multicolumn{18}{|l|}{ Morphological } \\
\hline Age (years) & 4487 & 14.7 & 2.2 & 462 & 11.5 & 0.8 & 493 & 11.6 & 0.8 & 0.128 & 1566 & 15.6 & 1.5 & 1966 & 15.6 & 1.5 & 0.130 \\
\hline Body weight (kg) & 4434 & 58.7 & 15.2 & 458 & 46.7 & 13.9 & 486 & 47.1 & 13.1 & 0.343 & 1556 & 64.8 & 14.5 & 1934 & 59.4 & 13.1 & 0.001 \\
\hline Height $(\mathrm{cm})$ & 4444 & 159.3 & 10.5 & 458 & 147.4 & 9.1 & 487 & 148.3 & 8.8 & 0.023 & 1556 & 167.6 & 8.2 & 1943 & 158.3 & 6.2 & 0.001 \\
\hline BMI $\left(\mathrm{kg} / \mathrm{m}^{2}\right)$ & 4423 & 22.9 & 4.7 & 458 & 21.2 & 4.7 & 486 & 21.1 & 4.5 & 0.840 & 1551 & 23.0 & 4.5 & 1928 & 23.7 & 4.8 & 0.001 \\
\hline Overweight (\%) ${ }^{\mathrm{a}}$ & 1106 & 25.0 & - & 126 & 27.5 & - & 152 & 31.3 & - & 0.001 & 357 & 23.0 & -- & 471 & 24.4 & $\cdots$ & 0.057 \\
\hline Obesity $(\%)^{\mathrm{a}}$ & 562 & 12.7 & - & 84 & 18.3 & - & 60 & 12.3 & - & 0.001 & 184 & 11.9 & -- & 234 & 12.1 & $\cdots$ & 0.063 \\
\hline \multicolumn{18}{|l|}{ Musculoskeletal } \\
\hline Standing long jump (cm) & 4169 & 147.3 & 34.6 & 442 & 138.8 & 22.4 & 471 & 121.6 & 19.6 & 0.001 & 1475 & 178.1 & 30.4 & 1781 & 130.7 & 23.4 & 0.001 \\
\hline \multicolumn{18}{|l|}{ Motor } \\
\hline $4 \times 10 \mathrm{~m}(\mathrm{~s})$ & 3837 & 13.0 & 1.5 & 379 & 13.3 & 1.2 & 395 & 14.2 & 1.6 & 0.001 & 1432 & 12.01 & 1.3 & 1631 & 13.5 & 1.2 & 0.001 \\
\hline \multicolumn{18}{|c|}{ Cardiorespiratory 20-m SRT } \\
\hline 20-m laps (no.) & 4196 & 35.8 & 22.4 & 449 & 29.8 & 17.2 & 474 & 19.9 & 11.6 & 0.001 & 1500 & 53.4 & 23.6 & 1773 & 26.8 & 13.6 & 0.001 \\
\hline Complete stage (no.) & 4196 & 4.3 & 2.5 & 449 & 3.4 & 2.0 & 474 & 2.4 & 1.4 & 0.001 & 1500 & 6.0 & 2.5 & 1773 & 3.2 & 1.6 & 0.001 \\
\hline Speed $(\mathrm{km} / \mathrm{h})^{\mathrm{b}}$ & 4196 & 10.1 & 1.2 & 449 & 9.7 & 1.0 & 474 & 9.2 & 0.7 & 0.001 & 1500 & 10.9 & 1.2 & 1773 & 9.6 & 0.8 & 0.001 \\
\hline $\mathrm{VO}_{2 \max }(\mathrm{mL} / \mathrm{kg} / \mathrm{min})^{\mathrm{c}}$ & 4196 & 38.7 & 6.7 & 449 & 42.1 & 4.9 & 474 & 39.5 & 3.6 & 0.001 & 1500 & 42.5 & 6.6 & 1773 & 34.4 & 5.0 & 0.001 \\
\hline
\end{tabular}

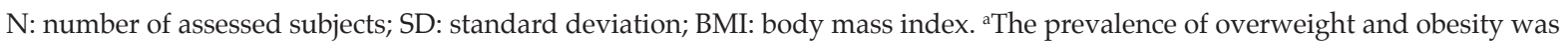
estimated based on Cole's criteria. ${ }^{16}$ bIt corresponds to the speed reached in the last complete stage of the 20-m SRT (coursenavette $20 \mathrm{~m}$ ). ${ }^{c}$ The maximal oxygen consumption was estimated based on the equation of Leger. ${ }^{18}$ 
Table 2 shows the PF standards for the cardiorespiratory component, and Table 3, for the musculoskeletal and motor components, classified by age and sex, expressed as $5^{\text {th }}, 2^{\text {th }}$, $50^{\text {th }}, 75^{\text {th }}$ and $95^{\text {th }}$ percentiles.

The percentile curves showed a mild halt and, in some cases, a reduction in the levels of PF among female participants (Figure 1).

On the contrary, PF levels increased among male participants (Figure 2).

\section{DISCUSSION}

Standards for the different PF components were developed, for a wide age range and both male and female students of Neuquén. These will allow physical education teachers to make decisions taking them as a reference and establish comparisons among different age groups, students, schools, provinces, and countries.
In the group of male participants, the cardiorespiratory component, the standing long jump test, and the $4 \times 10 \mathrm{~m}$ speed test increased with age. Likewise, in the group of female participants, performance in the PF tests improved until 15 years old and then stabilized. This is probably because, in average, girls reach maturity before boys and, at 15 years, they are already in the final stage of maturation. ${ }^{15}$

Males showed a better PF performance, which was consistent with several studies. ${ }^{10,16-18}$ Such difference was the result of various morphofunctional, psychosocial, and physical activity habit factors. ${ }^{9,20}$

\section{Physical fitness levels in relation to other Argentine provinces}

Only one study that had used the ALPHAFitness test battery in Argentina was found in

TABLE 2. Percentile values for the cardiorespiratory component (20-m SRT) in both males and females

\begin{tabular}{|c|c|c|c|c|c|c|c|c|c|c|c|c|c|c|c|c|c|c|c|}
\hline \multicolumn{10}{|c|}{ FEMALE } & \multicolumn{10}{|c|}{ MALE } \\
\hline Age & $\mathrm{N}$ & $\mathrm{L}$ & $M$ & $\mathrm{~S}$ & P5 & P25 & P50 & P75 & P95 & Age & $\mathrm{N}$ & $\mathrm{L}$ & $M$ & $S$ & P5 & P25 & P50 & P75 & P95 \\
\hline \multicolumn{10}{|c|}{ Stages (no.) } & \multicolumn{10}{|c|}{ Stages (no.) } \\
\hline 10 & 119 & -0.16 & 1.80 & 0.56 & 0.9 & 1.2 & 1.8 & 2.7 & 4.0 & 10 & 136 & 0.08 & 2.44 & 0.66 & 1.0 & 1.6 & 2.4 & 3.8 & 5.7 \\
\hline 11 & 181 & -0.06 & 2.01 & 0.56 & 1.0 & 1.4 & 2.0 & 2.9 & 4.3 & 11 & 160 & 0.27 & 2.94 & 0.61 & 1.2 & 1.9 & 2.9 & 4.3 & 6.1 \\
\hline 12 & 172 & 0.03 & 2.27 & 0.55 & 1.1 & 1.6 & 2.3 & 3.3 & 4.7 & 12 & 149 & 0.45 & 3.58 & 0.56 & 1.5 & 2.4 & 3.6 & 5.0 & 6.8 \\
\hline 13 & 319 & 0.11 & 2.54 & 0.55 & 1.2 & 1.7 & 2.5 & 3.6 & 5.1 & 13 & 248 & 0.61 & 4.38 & 0.51 & 1.8 & 3.0 & 4.4 & 6.0 & 7.7 \\
\hline 14 & 344 & 0.18 & 2.70 & 0.53 & 1.3 & 1.9 & 2.7 & 3.8 & 5.3 & 14 & 349 & 0.74 & 5.27 & 0.46 & 2.3 & 3.7 & 5.3 & 6.9 & 8.7 \\
\hline 15 & 391 & 0.23 & 2.92 & 0.52 & 1.4 & 2.0 & 2.9 & 4.1 & 5.5 & 15 & 307 & 0.87 & 6.10 & 0.41 & 2.9 & 4.5 & 6.1 & 7.8 & 9.6 \\
\hline 16 & 306 & 0.27 & 3.08 & 0.50 & 1.5 & 2.2 & 3.1 & 4.3 & 5.7 & 16 & 257 & 0.99 & 6.65 & 0.37 & 3.4 & 5.0 & 6.7 & 8.3 & 9.9 \\
\hline 17 & 295 & 0.30 & 3.13 & 0.49 & 1.5 & 2.2 & 3.1 & 4.3 & 5.7 & 17 & 256 & 1.10 & 7.02 & 0.33 & 3.9 & 5.5 & 7.0 & 8.5 & 10.0 \\
\hline 18 & 118 & 0.33 & 3.13 & 0.47 & 1.5 & 2.2 & 3.1 & 4.2 & 5.6 & 18 & 73 & 1.22 & 7.14 & 0.30 & 4.2 & 5.7 & 7.1 & 8.5 & 9.9 \\
\hline \multicolumn{10}{|c|}{ Speed reached $(\mathrm{km} / \mathrm{h})$} & \multicolumn{10}{|c|}{ Speed reached $(\mathrm{km} / \mathrm{h})$} \\
\hline 10 & 119 & -6.25 & 8.96 & 0.06 & 8.4 & 8.7 & 9.0 & 9.4 & 9.9 & 10 & 136 & -3.29 & 9.31 & 0.09 & 8.4 & 8.8 & 9.3 & 9.9 & 10.8 \\
\hline 11 & 181 & -5.61 & 9.05 & 0.06 & 8.5 & 8.7 & 9.1 & 9.5 & 10.1 & 11 & 160 & -2.29 & 9.53 & 0.09 & 8.5 & 9.0 & 9.5 & 10.2 & 11.0 \\
\hline 12 & 172 & -4.98 & 9.17 & 0.07 & 8.5 & 8.8 & 9.2 & 9.6 & 10.3 & 12 & 149 & -1.33 & 9.82 & 0.10 & 8.7 & 9.2 & 9.8 & 10.5 & 11.4 \\
\hline 13 & 319 & -4.39 & 9.29 & 0.07 & 8.6 & 8.9 & 9.3 & 9.8 & 10.5 & 13 & 248 & -0.48 & 10.22 & 0.10 & 8.9 & 9.5 & 10.2 & 11.0 & 11.8 \\
\hline 14 & 344 & -3.87 & 9.37 & 0.07 & 8.6 & 9.0 & 9.4 & 9.9 & 10.6 & 14 & 349 & 0.24 & 10.66 & 0.11 & 9.2 & 9.9 & 10.7 & 11.5 & 12.3 \\
\hline 15 & 391 & -3.45 & 9.47 & 0.07 & 8.7 & 9.0 & 9.5 & 10.0 & 10.7 & 15 & 307 & 0.82 & 11.08 & 0.11 & 9.5 & 10.3 & 11.1 & 11.9 & 12.7 \\
\hline 16 & 306 & -3.14 & 9.55 & 0.08 & 8.7 & 9.1 & 9.6 & 10.1 & 10.8 & 16 & 257 & 1.26 & 11.36 & 0.11 & 9.7 & 10.5 & 11.4 & 12.2 & 12.9 \\
\hline 17 & 295 & -2.91 & 9.58 & 0.08 & 8.8 & 9.1 & 9.6 & 10.1 & 10.8 & 17 & 256 & 1.64 & 11.52 & 0.10 & 9.9 & 10.7 & 11.5 & 12.3 & 13.0 \\
\hline 18 & 118 & -2.73 & 9.59 & 0.08 & 8.8 & 9.1 & 9.6 & 10.1 & 10.8 & 18 & 73 & 1.98 & 11.55 & 0.10 & 9.9 & 10.8 & 11.5 & 12.3 & 13.0 \\
\hline \multicolumn{10}{|c|}{ Estimated $\mathrm{VO}_{2 \max }(\mathrm{mL} / \mathrm{kg} / \mathrm{min})$} & \multicolumn{10}{|c|}{ Estimated $\mathrm{VO}_{2 \max }(\mathrm{mL} / \mathrm{kg} / \mathrm{min})$} \\
\hline 10 & 119 & -5.66 & 41.27 & 0.06 & 38.7 & 39.9 & 41.3 & 43.1 & 45.6 & 10 & 136 & -2.77 & 43.03 & 0.09 & 38.8 & 40.7 & 43.0 & 46.0 & 49.8 \\
\hline 11 & 181 & -4.82 & 39.89 & 0.07 & 37.0 & 38.3 & 39.9 & 42.0 & 45.0 & 11 & 160 & -1.87 & 42.26 & 0.10 & 37.3 & 39.6 & 42.3 & 45.6 & 49.7 \\
\hline 12 & 172 & -3.99 & 38.65 & 0.08 & 35.3 & 36.8 & 38.7 & 41.1 & 44.5 & 12 & 149 & -1.01 & 41.96 & 0.12 & 36.2 & 38.9 & 42.0 & 45.6 & 49.9 \\
\hline 13 & 319 & -3.23 & 37.44 & 0.09 & 33.8 & 35.4 & 37.4 & 40.1 & 43.8 & 13 & 248 & -0.25 & 42.27 & 0.13 & 35.5 & 38.7 & 42.3 & 46.2 & 50.7 \\
\hline 14 & 344 & -2.57 & 36.04 & 0.10 & 32.0 & 33.8 & 36.0 & 38.9 & 42.7 & 14 & 349 & 0.36 & 43.00 & 0.14 & 35.2 & 39.0 & 43.0 & 47.3 & 51.8 \\
\hline 15 & 391 & -2.03 & 34.79 & 0.11 & 30.5 & 32.4 & 34.8 & 37.8 & 41.7 & 15 & 307 & 0.82 & 43.71 & 0.15 & 35.0 & 39.3 & 43.7 & 48.2 & 52.7 \\
\hline 16 & 306 & -1.62 & 33.45 & 0.12 & 28.9 & 30.9 & 33.5 & 36.6 & 40.6 & 16 & 257 & 1.14 & 43.69 & 0.16 & 34.4 & 39.1 & 43.7 & 48.2 & 52.7 \\
\hline 17 & 295 & -1.30 & 31.81 & 0.13 & 27.1 & 29.2 & 31.8 & 35.0 & 39.0 & 17 & 256 & 1.38 & 43.15 & 0.16 & 33.4 & 38.4 & 43.1 & 47.7 & 52.1 \\
\hline 18 & 118 & -1.03 & 30.08 & 0.14 & 25.2 & 27.4 & 30.1 & 33.3 & 37.3 & 18 & 73 & 1.58 & 41.90 & 0.17 & 32.0 & 37.1 & 41.9 & 46.4 & 50.6 \\
\hline
\end{tabular}


the bibliography. That study was carried out in male and female children and adolescents aged 6-19 years $(n=1867)$ from five provinces (Mendoza, Entre Ríos, Buenos Aires, Santa Cruz, and Misiones). ${ }^{10}$ Compared to our study, similar average values were observed for the following: BMI $\left(20.8 \mathrm{~kg} / \mathrm{m}^{2}\right.$ versus $\left.22.9 \mathrm{~kg} / \mathrm{m}^{2}\right)$, overweight (20.5\% versus $27.5 \%$ ), SLJ (148.7 cm versus $147.3 \mathrm{~cm}), 4 \times 10 \mathrm{~m}$ test (12.7 s versus $13.0 \mathrm{~s})$, and 20-m SRT: number of laps (36.2 versus 35.8 ), speed $(10.1 \mathrm{~km} / \mathrm{h}$ versus $10.2 \mathrm{~km} / \mathrm{h})$, and $\mathrm{VO}_{2 \max }$ (41.5 mL $/ \mathrm{kg} / \mathrm{min}$ versus $39.3 \mathrm{~mL} / \mathrm{kg} / \mathrm{min}$ ).

The comparison of the $50^{\text {th }}$ percentile in this study and in that by Secchiet al., ${ }^{10}$ showed the following: the cardiorespiratory, musculoskeletal, and motor components were lower at all ages among the female participants of Neuquén. The males of Neuquén showed a worse performance in the cardiorespiratory component between 11 and 13 years, and similar values were observed between 14 and 17 years. In the musculoskeletal and motor components, values were slightly lower in all age groups.
Such differences, which were mainly observed in the group of female participants, may be due to different reasons: the number of assessed subjects ( $n=1867$ versus $n=4480)$, the number of participating schools (16 versus 42 ), and school characteristics (in the study by Secchi et al., $37 \%$ were private schools, while in our study, $100 \%$ were public schools).

Specifically in terms of overweight and obesity, our values were compared to those obtained in three other Argentine studies. ${ }^{10,21,22}$ Secchi et al., ${ }^{10}$ observed differences in the percentage of obesity, which was higher in Neuquén $(7.8 \%$ versus $18.3 \%$ ), mainly in the adolescent group, for the group of male and female participants: $3.9 \%$ versus $11.9 \%$ and $4.1 \%$ versus $12.1 \%$, respectively. Sapaget al., ${ }^{21}$ found similar values in the children and adolescents of Neuquén $(n=331)$ aged $6-15$ years; $20.8 \%$ were overweight and $22 \%$, obese. Kovalskys et al., ${ }^{22}$ observed similar overweight values $(20.8 \%)$ in a sample of children and adolescents who attended a pediatric office visit $(\mathrm{n}=1289)$ but lower obesity values $(5.4 \%)$.

TABLE 3. Percentile values for the lower limb strength test (standing long jump) and agility/speed test (4x 10) in both males and females

\begin{tabular}{|c|c|c|c|c|c|c|c|c|c|c|c|c|c|c|c|c|c|c|c|}
\hline \multicolumn{10}{|c|}{ MALE } & \multicolumn{10}{|c|}{ FEMALE } \\
\hline Age & $\mathrm{N}$ & $\mathrm{L}$ & $\mathrm{M}$ & $S$ & P5 & P25 & P50 & P75 & P95 & Age & $\mathrm{N}$ & L & $M$ & $\mathrm{~S}$ & P5 & P25 & P50 & P75 & P95 \\
\hline \multicolumn{10}{|c|}{ Standing long jump (cm) } & \multicolumn{10}{|c|}{ Standing long jump (cm) } \\
\hline 10 & 135 & 0.80 & 132.12 & 0.16 & 103.7 & 117.8 & 132.1 & 146.8 & 161.8 & 10 & 122 & 0.64 & 118.58 & 0.16 & 93.9 & 106.0 & 118.6 & 131.7 & 145.3 \\
\hline 11 & 157 & 1.01 & 138.34 & 0.16 & 108.1 & 123.2 & 138.3 & 153.4 & 168.5 & 11 & 178 & 0.56 & 121.30 & 0.17 & 95.6 & 108.1 & 121.3 & 135.2 & 149.7 \\
\hline 12 & 146 & 1.23 & 146.39 & 0.16 & 113.8 & 130.3 & 146.4 & 162.0 & 177.4 & 12 & 169 & 0.51 & 123.63 & 0.17 & 96.9 & 109.9 & 123.6 & 138.2 & 153.6 \\
\hline 13 & 259 & 1.43 & 158.03 & 0.16 & 122.6 & 140.8 & 158.0 & 174.5 & 190.3 & 13 & 317 & 0.51 & 126.08 & 0.18 & 98.1 & 111.7 & 126.1 & 141.3 & 157.5 \\
\hline 14 & 354 & 1.56 & 171.06 & 0.16 & 133.2 & 152.8 & 171.1 & 188.3 & 204.7 & 14 & 357 & 0.57 & 127.21 & 0.18 & 98.3 & 112.4 & 127.2 & 142.8 & 159.2 \\
\hline 15 & 302 & 1.65 & 182.10 & 0.15 & 143.1 & 163.3 & 182.1 & 199.7 & 216.3 & 15 & 401 & 0.59 & 129.62 & 0.18 & 100.1 & 114.5 & 129.6 & 145.5 & 162.2 \\
\hline 16 & 253 & 1.74 & 189.96 & 0.14 & 150.6 & 171.1 & 190.0 & 207.5 & 224.0 & 16 & 307 & 0.55 & 131.92 & 0.18 & 102.3 & 116.7 & 131.9 & 148.0 & 164.9 \\
\hline 17 & 242 & 1.84 & 195.13 & 0.14 & 156.1 & 176.5 & 195.1 & 212.4 & 228.5 & 17 & 298 & 0.49 & 132.98 & 0.18 & 103.6 & 117.8 & 133.0 & 149.1 & 166.1 \\
\hline 18 & 65 & 1.94 & 197.53 & 0.13 & 159.3 & 179.3 & 197.5 & 214.3 & 229.9 & 18 & 101 & 0.43 & 132.96 & 0.17 & 104.1 & 118.0 & 133.0 & 149.0 & 166.0 \\
\hline \multicolumn{10}{|c|}{$4 \times 10(s)$} & \multicolumn{10}{|c|}{$4 \times 10$ (s) } \\
\hline 10 & 119 & -1.90 & 13.26 & 0.09 & 11.9 & 12.5 & 13.3 & 14.1 & 15.1 & 10 & 110 & -2.15 & 14.34 & 0.10 & 12.8 & 13.5 & 14.3 & 15.4 & 16.8 \\
\hline 11 & 133 & -2.11 & 13.15 & 0.09 & 11.8 & 12.4 & 13.1 & 14.0 & 15.1 & 11 & 152 & -1.92 & 13.97 & 0.10 & 12.4 & 13.1 & 14.0 & 15.0 & 16.2 \\
\hline 12 & 123 & -2.31 & 12.86 & 0.09 & 11.5 & 12.1 & 12.9 & 13.7 & 14.9 & 12 & 132 & -1.73 & 13.67 & 0.10 & 12.2 & 12.9 & 13.7 & 14.6 & 15.8 \\
\hline 13 & 251 & -2.43 & 12.42 & 0.09 & 11.1 & 11.7 & 12.4 & 13.3 & 14.4 & 13 & 294 & -1.63 & 13.52 & 0.09 & 12.1 & 12.7 & 13.5 & 14.4 & 15.5 \\
\hline 14 & 343 & -2.46 & 11.97 & 0.09 & 10.8 & 11.3 & 12.0 & 12.8 & 13.8 & 14 & 320 & -1.62 & 13.44 & 0.09 & 12.0 & 12.7 & 13.4 & 14.3 & 15.3 \\
\hline 15 & 296 & -2.39 & 11.72 & 0.09 & 10.5 & 11.1 & 11.7 & 12.5 & 13.5 & 15 & 361 & -1.62 & 13.37 & 0.09 & 12.0 & 12.6 & 13.4 & 14.2 & 15.2 \\
\hline 16 & 249 & -2.14 & 11.61 & 0.09 & 10.5 & 11.0 & 11.6 & 12.4 & 13.3 & 16 & 281 & -1.55 & 13.33 & 0.09 & 12.0 & 12.6 & 13.3 & 14.2 & 15.1 \\
\hline 17 & 229 & -1.76 & 11.50 & 0.09 & 10.3 & 10.9 & 11.5 & 12.2 & 13.1 & 17 & 278 & -1.41 & 13.36 & 0.09 & 12.0 & 12.6 & 13.4 & 14.2 & 15.1 \\
\hline 18 & 64 & -1.36 & 11.44 & 0.09 & 10.3 & 10.8 & 11.4 & 12.1 & 13.0 & 18 & 97 & -1.23 & 13.42 & 0.09 & 12.1 & 12.7 & 13.4 & 14.2 & 15.2 \\
\hline
\end{tabular}


Probably, such difference is due to the fact that the study was conducted 15 years ago, and that eating and physical activity habits may have changed.

\section{Differences in physical fitness levels in relation to other countries of America}

PF levels were compared by sex in a total of seven studies, all conducted in American populations (leaving out the study by Secchi et al., ${ }^{10}$ mentioned above).

The levels of lower limb strength in both male and female participants were similar to those observed in two studies from Chile and Uruguay. ${ }^{16,23}$ The speed/agility levels in both male and female participants were similar to those found in a study from Uruguay. ${ }^{23}$

The cardiorespiratory component outcomes in both male and female participants were similar to those of three studies from Uruguay, Chile, and Colombia, $16,23,24$ but lower than those of three other studies from Canada, ${ }^{25}$ Colombia (adjusted for altitude) ${ }^{17}$, and Colombia (ethnicity). ${ }^{26}$

Lastly, it is worth noting a limitation of this study: rural schools were not included due to logistical reasons.

\section{CONCLUSIONS}

This study provides the first PF standards for male and female children and adolescents of the province of Neuquén, Argentina.

\section{Acknowledgments}

We would like to thank the Department of Sports and Youth of the province of Neuquén for funding this project and the support of the Ministry of Education of the province of Neuquén.

Figure 1. Percentile curve (bottom-up: P5, P25, P50, P75, P95) of physical fitness in relation to the health of female participants

Physical fitness levels in female children and adolescents of Neuquén, Argentina (P5, P25, P75, P95)
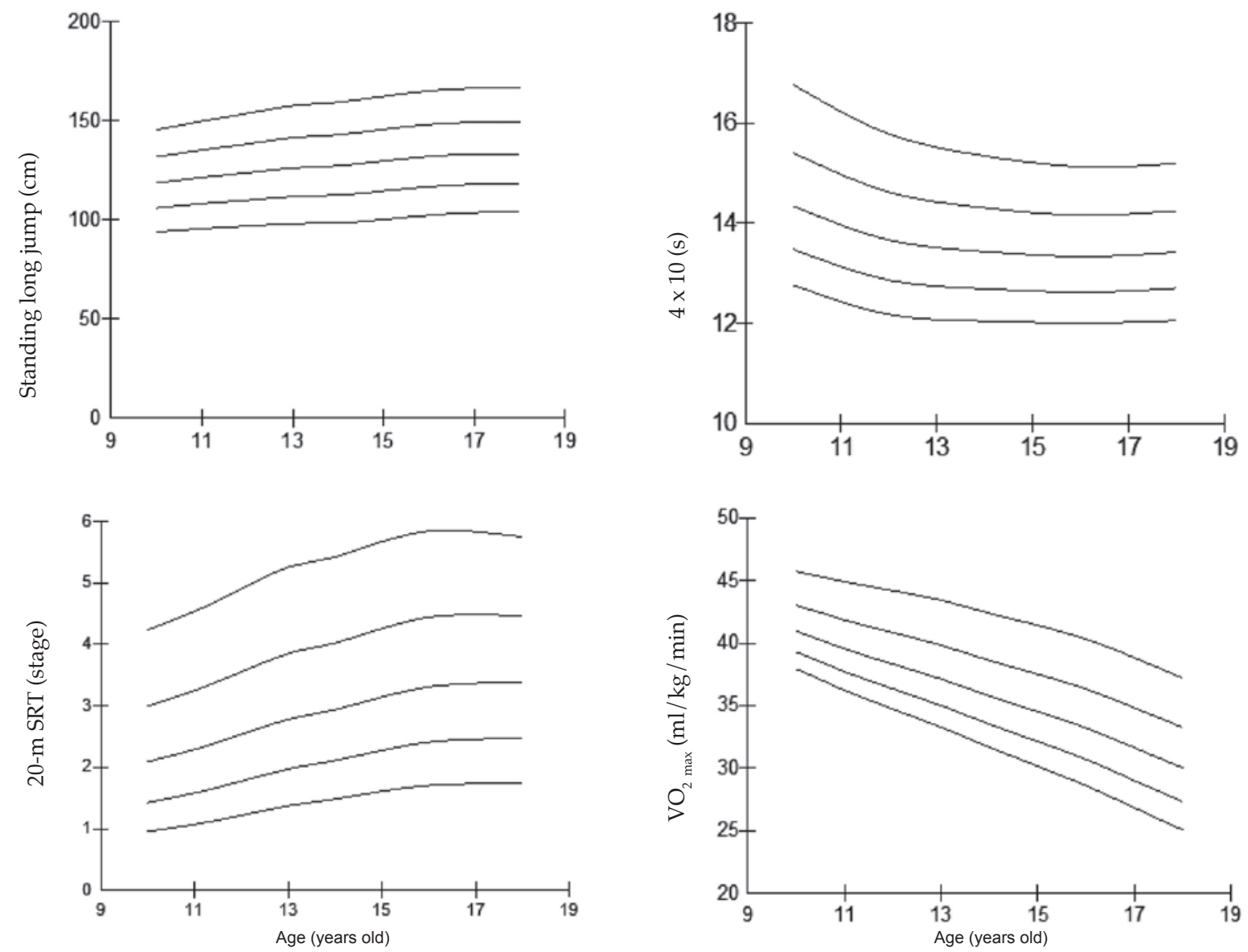


\section{REFERENCES}

1. Caspersen CJ, Powell KE, Christenson GM. Physical activity, exercise, and physical fitness: definitions and distinctions for health-related research. Public Health Rep. 1985; 100(2):12631.

2. Castillo-Garzón MJ, Ruiz JR, Ortega FB, Gutiérrez A. Antiaging therapy through fitness enhancement. Clin Interv Aging. 2006; 1(3):213-20.

3. Ortega FB, RuizJR, Castillo MJ, Sjöström M. Physical fitness in childhood and adolescence: a powerful marker of health. Int J Obes (Lond). 2008; 32(1):1-11.

4. Ortega FB, Campos D, Cadenas-Sanchez C, Altmäe S, et al. Physical fitness and shapes of subcortical brain structures in children. Br J Nutr. 2017; 27:1-10.

5. Steele RM, Brage S, Corder K, Wareham NJ, et al. Physical activity, cardiorespiratory fitness, and the metabolic syndrome in youth. J Appl Physiol. 2008; 105(1):342-51.

6. Burns RD, Brusseau TA. Muscular strength and endurance and cardio-metabolic health in disadvantaged Hispanic children from the U.S. Prev Med Rep. 2016; 9(5):21-6.

7. SecchiJD, García GC, Arcuri CR. Evaluación de la Condición Física en el ámbito escolar: un enfoque práctico para interpretar e informa resultados. Enfoques. 2016; 28(2):67-87.

8. España-Romero V, Artero EG, Jimenez-Pavón D, CuencaGarcía M, et al. Assessing health-related fitness tests in the school setting: reliability, feasibility and safety; the ALPHA Study. Int J Sports Med. 2010; 31(7):490-7.

9. Ruiz JR, Castro-Piñero J, España-Romero V, Artero EG, et al. Field-based fitness assessment in young people: the ALPHA health-related fitness test battery for children and adolescents. Br J Sports Med. 2011; 45(6):518-24.

10. Secchi JD, García GC, España-Romero V, Castro-Piñero J. Condición física y riesgo cardiovascular futuro en niños y adolescentes argentinos: una introducción de la batería ALPHA. Arch Argent Pediatr. 2014; 112(2):132-40.

11. Secchi JD, García GC, Arcuri CR. ¿Evaluar la condición física en la escuela? Conceptos y discusiones planteadas en el ámbito de la educación física y la ciencia. Enfoques. 2016; 28(1):67-92.

12. Cole TJ, Bellizzi MC, Flegal KM, Dietz WH. Establishing a standard definition for child overweight and obesity worldwide: international survey. BMJ. 2000;320(7244):12403.

13. García GC, Secchi JD. Test coursenavette de 20 metros con etapas de un minuto. Una idea original que perdura hace 30 años. ApuntsMedEsport. 2014; 49(183):93-103.

14. Léger LA, MercierD, Gadoury C, LambertJ. The multistage 20 metre shuttle run test for aerobic fitness. J Sports Sci. 1988; 6(2):93-101.

15. Lejarraga H, Orfila G. Estándares de peso y estatura para

Figure 2. Percentile curve (bottom-up: P5, P25, P50, P75, P95) of physical fitness in relation to the health of male participants

Physical fitness levels in male children and adolescents of Neuquén, Argentina

(P5, P25, P75, P95)
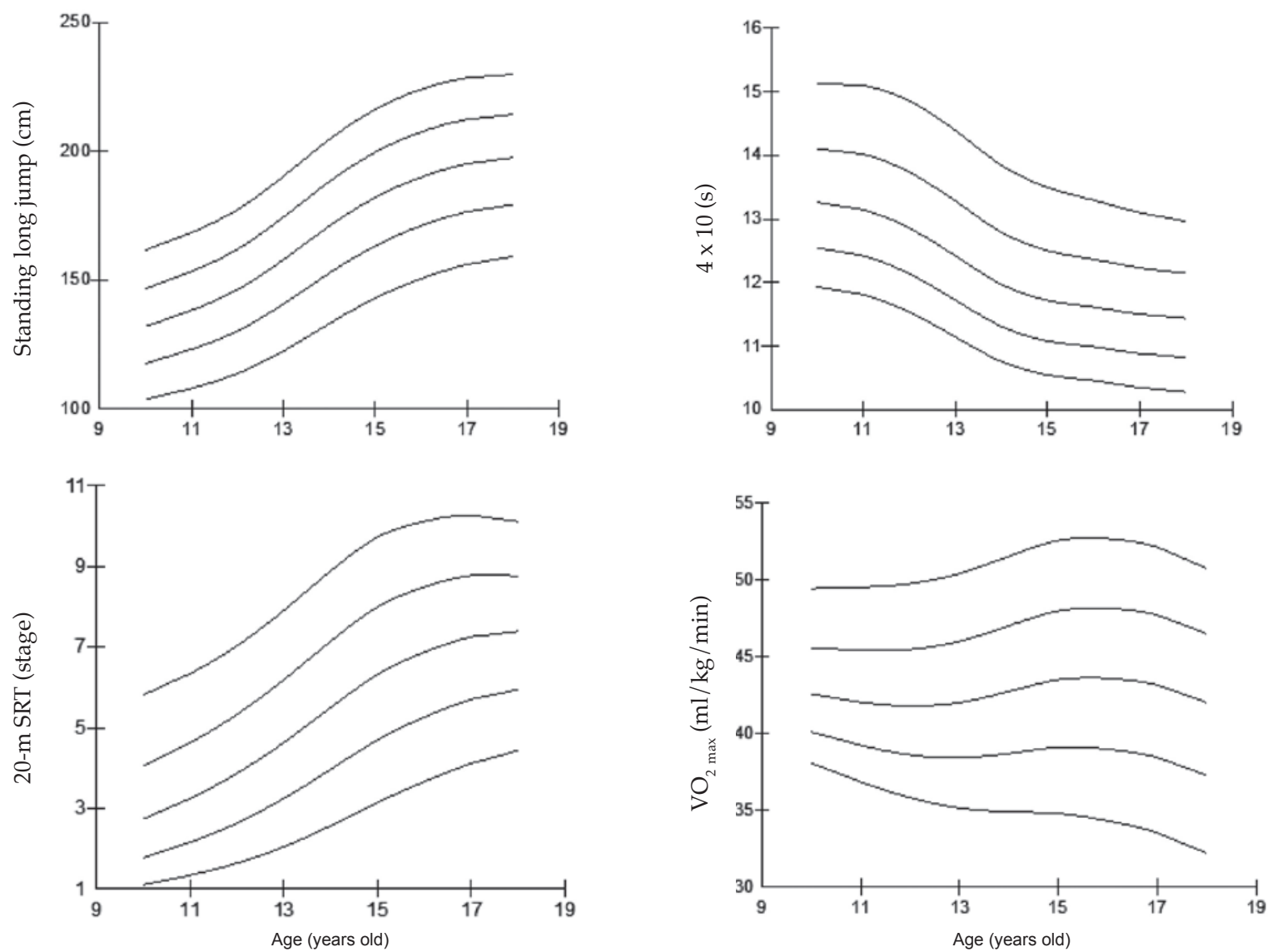
niñas y niños argentinos desde el nacimiento hasta la madurez. Arch Argent Pediatr. 1987; 85(4):209-22.

16. Garber MD, Sajuria M, Lobelo F. Geographical variation in health-related physical fitness and body composition among Chilean $8^{\text {th }}$ graders: a nationally representative cross-sectional study. PLoS One. 2014; 25(9):e108053.

17. Ramírez-Vélez R, Palacios-López A, Humberto PrietoBenavides D, Enrique Correa-Bautista J, et al. Normative reference values for the $20 \mathrm{~m}$ shuttle-run test in a populationbased sample of school-aged youth in Bogota, Colombia: the FUPRECOL study. Am J Hum Biol. 2017; 29(1):4-14.

18. Bustamante A, Beunen G, Maia J. Valoración de la aptitud física en niños y adolescentes: construcción de cartas percentílicas para la región central del Perú. Rev Peru Med Exp Salud Pública. 2012; 29(2):188-97.

19. D'Angelo CP, Agüero A, Ghioldi M, Saco $M$, et al. Evaluación morfofuncional, psicosocial y de hábitos alimentarios de los alumnos de las Escuelas Públicas de la Ciudad de Buenos Aires. Rev Asoc Méd Argent. 2005; 118(1):9-22.

20. Santander MD. Sobrepeso y obesidad y su relación con el sedentarismo y patrones de actividad física en adolescentes neuquinos. [Public Health Master Dissertation]. Buenos Aires: Facultad de Medicina de la Universidad de Buenos Aires; 2017.
21. Sapag M, Dioverti C, Paramio L, Petronace A, et al. Evaluación nutricional y de tensión arterial en niños de dos escuelas de población vulnerable de Cutral Co y Plaza Huincul: estudio cuantitativo y cualitativo. Arch Argent Pediatr. 2014; 112(4):337-44.

22. Kovalskys I, Bay L, RauschHerscovici C, Berner E. Prevalencia de obesidad en una población de 10 a 19 años en la consulta pediatrica. Arch Argent Pediatr. 2003; 101(6):441-7.

23. Gioscia G, Beretervide S, Bermúdez G, Quagliatta D. Valoración de la condición física en estudiantes de secundaria de Montevideo y área metropolitana, Uruguay. Rev Univ Educ Fís Deporte. 2017; 10:8-15.

24. Ramírez-Vélez R, García-Hermoso A, Agostinis-Sobrinho C, Mota J, et al. Pubertal Stage, Body Mass Index, and Cardiometabolic Risk in Children and Adolescents in Bogotá, Colombia: The Cross-Sectional Fuprecol Study. Nutrients. 2017; 9(7):E644.

25. Leger L, Lambert J, Goulet A, Rowan C, et al. Capacite aerobie des Quebecois de 6 a 17 ans -Test navette de 20 metres avecpaliers de 1 minute. Can J Appl Sport Sci. 1984; 9(2):64-9.

26. Ramírez-Vélez R, Correa-BautistaJE, Ramos-Sepúlveda JA, Piñeros-Sepúlveda JA, et al. Aerobic capacity and future cardiovascular risk in Indian community from a low-income area in Cauca, Colombia. Ital J Pediatr. 2017; 43(1):28. 